\title{
The Role of Ethnic and National Identifications in Perceived Discrimination for Asian Americans: Toward a Better Understanding of the Buffering Effect of Group Identifications on Psychological Distress
}

\author{
Que-Lam Huynh \\ California State University, Northridge \\ Thierry Devos and Robyn Goldberg \\ San Diego State University
}

This is a postprint/accepted version of the manuscript. It is now published:

Huynh, Q.-L., Devos, T., \& Goldberg, R. (2014). The role of ethnic and national identifications in perceived discrimination for Asian Americans: Toward a better understanding of the buffering effect of group identifications on psychological distress. Asian American Journal of Psychology, 5, 161-171. https://doi.org/10.1037/a0031601

Please cite the published version. The version available on PsyArXiv is before journal proof. The published version might be slightly different.

This research was supported in part by National Institute of Mental Health Grants R24 MH 065515 and 3R24 MH 065515-06S1.

Correspondence concerning this article should be addressed to Que-Lam Huynh, Department of Psychology, California State University, Northridge, 18111 Nordhoff Street, Northridge, CA 91330-8255. E-mail: huynh.quelam@gmail.com 


\begin{abstract}
A robust relationship between perceived racial discrimination and psychological distress has been established. Yet, mixed evidence exists regarding the extent to which ethnic identification moderates this relationship, and scarce attention has been paid to the moderating role of national identification. We propose that the role of group identifications in the perceived discriminationpsychological distress relationship is best understood by simultaneously and interactively considering ethnic and national identifications. A sample of 259 Asian American students completed measures of perceived discrimination, group identifications (specific ethnic identification stated by respondents and national or "mainstream American" identification), and psychological distress (anxiety and depression symptoms). Regression analyses revealed a significant three-way interaction of perceived discrimination, ethnic identification, and national identification on psychological distress. Simple-slope analyses indicated that dual identification (strong ethnic and national identifications) was linked to a weaker relationship between perceived discrimination and psychological distress compared to other group identification configurations. These findings underscore the need to consider the interconnections between ethnic and national identifications to better understand the circumstances under which group identifications are likely to buffer individuals against the adverse effects of racial discrimination.
\end{abstract}

Keywords: perceived discrimination, Asian Americans, ethnic identity, national identity, bicultural identity, anxiety, depression, Schedule of Racist Events 
The Role of Ethnic and National Identifications in Perceived Discrimination for Asian Americans: Toward a Better Understanding of the Buffering Effect of Group Identifications on Psychological Distress

Much empirical research has demonstrated a consistent link between perceived discrimination and psychological distress (see Pascoe \& Smart Richman, 2009 for a metaanalysis). Increasingly, researchers are examining variables that may attenuate (i.e., protective factors) or intensify (i.e., risk factors) this relationship. In the realm of ethnic or racial discrimination, the role of ethnic identification has received the most attention. A common assumption is that ethnic identification may buffer individuals against the adverse impact of discrimination: strongly identifying with one's ethnic group (e.g., with Filipino Americans) would provide psychological and social resources to deal with experiences of discrimination. However, the empirical evidence for this proposition is less than compelling. In fact, most studies have not found a significant moderating effect of ethnic identification (Pascoe \& Smart Richman, 2009). Here, we suggest that focusing exclusively on ethnic identification obscures crucial aspects of group identity dynamics. More precisely, we argue that important insights can be gained by also examining the extent to which members of an ethnic minority group identify with a broader and more inclusive entity, namely their national (or mainstream American) identity. Based on research on acculturation and multiple social identities (Berry, Phinney, Sam, \& Vedder, 2006; Hornsey \& Hogg, 2000; Nguyen \& Benet-Martínez, 2010), we developed and tested the idea that a better understanding of the role of group identification requires taking simultaneously and interactively into account the strength of ethnic and national identifications. By considering identity configurations obtained when these two independent dimensions are crossed, we are likely to better grasp the circumstances under which group identification may 
operate as a protective factor. Filling this gap in the literature, we examined the moderating role of ethnic and national identifications in the perceived discrimination-psychological distress relationship for Asian Americans, an under-studied ethnic minority group in this realm.

Asian Americans have experienced a long history of systemic, institutionalized discrimination (racism) in the United States, ranging from restrictive immigration quotas to being denied citizenship rights (Takaki, 1998). Much of the history of mainstream American treatment of Asian Americans consists of either a "yellow peril" image of Asians as unscrupulous and threatening to the American way of life, or a "model minority" image of Asians as academically high-achieving individuals who develop into diligent and docile workers. Asian Americans also experience discrimination at the personal level. For example, Asian Americans report facing various forms of racial microaggressions, such as being stereotyped as foreigners even if they were born in the United States (Huynh, Devos, \& Smalarz, 2011), being treated as the exoticized "other" in inter-racial interactions (Sue et al., 2007), and being denied the American identity (Cheryan \& Monin, 2005). In other words, Asian Americans continue to experience discrimination at institutional and individual levels (Goto, Gee, \& Takeuchi, 2002).

There is ample empirical evidence for the relationship between perceived discrimination and psychological distress for various ethnic minority groups, including Asian Americans (e.g., Cheng, Fancher, Ratanasen, Conner, Duberstein, Sue, \& Takeuchi, 2010; Gee, Spencer, Chen, Yip, \& Takeuchi, 2007; Greene, Way, \& Pahl, 2006; Hahm, Ozonoff, Gaumond, \& Sue, 2010; Pascoe \& Smart Richman, 2009; Romero, Carvajal, Volle, \& Orduña, 2007; Syed \& Juan, 2012), and there are several reasons why chronic perceived discrimination is related to poorer adjustment. First, discrimination can lead to affective reactions (e.g., anger, shock, sadness) that in turn shape people's perceptions of their world (Harrell, 2000). Second, discrimination may 
threaten people's sense of control and lead to learned helplessness (Perlow, Danoff-Burg, Swenson, \& Pulgiano, 2004) or reinforce inferior social status, thereby impacting self-esteem and self-concept (DuBois, Burk-Braxton, Swenson, Tevendale, \& Hardesty, 2002). In addition, due to the more ambiguous, subtle, and covert nature of contemporary ethnic and racial discrimination (Sue et al., 2007), individuals who encounter discrimination may ruminate over the events, which is a risk factor for depression (Harrell, 2000; Nolen-Hoeksema, Larson, \& Grayson, 1999). Taken together, perceived discrimination can be conceptualized as a life stressor that can broadly impact both mental and physical health of people who belong to an ethnic minority group (Clark, Anderson, Clark, \& Williams, 1999; Gee et al., 2007; Pascoe \& Smart Richman, 2009; U.S. Department of Health and Human Services, 2001). It is worth stressing that most of the work on the racial discrimination-psychological distress relationship has been based on African Americans. As a result, less is known about this issue for other ethnic or racial minority groups, including Asian Americans. Nonetheless, based on the available empirical evidence, including nationally representative data from the National Latino and Asian American Study (Gee et al., 2007), a longitudinal study on Asian American mental health (Greene et al., 2006), and a meta-analysis indicating that there were no ethnic differences on the discrimination-mental health relationship across 105 samples (Pascoe \& Smart Richman, 2009), it is clear that perceived discrimination is related to psychological distress among Asian Americans.

Given the consistent relationship between perceived discrimination and psychological distress, researchers have examined moderators of this relationship, such as racial socialization experiences, attribution and coping styles, and group identification. Among these variables, ethnic identification has been examined most extensively (Pascoe \& Smart Richman, 2009). 
Ethnic identification is the sense of membership in one's culture of origin or race and one's feelings about this group membership (e.g., attitudes toward or sense of belonging to the Chinese, Chinese American, Asian, or Asian American group; Phinney \& Devich-Navarro, 1997). There are alternative theoretical perspectives regarding the buffering role of ethnic identification in the perceived discrimination-psychological distress linkage. Tracing back to Allport's (1954) influential writings on the nature of prejudice and to social identity theory (Tajfel \& Turner, 1986), the rejection-identification model posits that individuals who have experienced discrimination frequently are more likely to identify with their ethnic group, which in turn alleviates some of the harmful consequences of perceived discrimination (Branscombe, Schmitt, \& Harvey, 1999). On the other hand, the discounting hypothesis stipulates that individuals who strongly identify with the disadvantaged, minority group to which they belong are more likely to attribute negative outcomes to discrimination, and in doing so protect their self-concept and well-being (Crocker \& Major, 1989). Despite their differences, both perspectives assume that ethnic identification should be a protective factor against the adverse effects of perceived discrimination.

Ethnic identification also may be a risk factor in the perceived discriminationpsychological distress relationship. Based on rejection sensitivity theory (Downey \& Feldman, 1996), rejection in the form of racial discrimination may lead ethnic minority individuals to feel anxious about possible future rejections in this domain (i.e., ethnicity), and to feel disconnected and psychologically taxed as a result of the rejection. In other words, repeated exposure to racial discrimination may make individuals who strongly identify with their ethnic group more sensitive to rejection as compared to those who weakly identify with their ethnic group. Alternatively, increased identification with one's ethnic group may make one more vigilant for 
cues that signal that one is a target of discrimination, prejudice, or negative stereotypes (e.g., Barrett \& Swim, 1998; Steele, Spencer, \& Aronson, 2002). There are several possible reasons for this vigilance. First, self-preservation may play a role, such that an individual may be motivated to look for evidence that he/she is being discriminated against in order to protect him/herself from harm (Barrett \& Swim, 1998). Ego defense also may motivate vigilance, such that ethnic minority group members may be motivated to look for and protect themselves of threats to selfesteem, such as ethnic or racial discrimination (Allport, 1954). No matter the motive, these perspectives posit that ethnic identity may exacerbate the perceived discriminationpsychological distress relationship by increasing people's vigilance to discrimination.

In light of these competing theoretical arguments regarding the moderating role of ethnic identification, it is not too surprising that the available empirical evidence for the contribution of this variable (as a buffer or risk factor) is unclear. Some studies have yielded findings consistent with the notion that ethnic identification buffers the stress of discrimination. For example, a large-scale study of Filipino Americans revealed that as the strength of ethnic identification increased, the link between perceived discrimination and depressive symptoms decreased (Mossakowski, 2003). This is in line with the idea that having a sense of ethnic pride, involvement in ethnic practices, and cultural commitment to one's ethnic group may protect mental health (Williams, Spencer, \& Jackson, 1999). Other studies have produced more mixed evidence for the buffering role of ethnic identification (e.g., Cassidy, O’Connor, Howe, \& Warden, 2004), in some cases even suggesting that ethnic identification was related to increased negative effects of perceived discrimination for Asian Americans (Noh, Beiser, Kaspar, Hou, \& Rummens, 1999; Yoo \& Lee, 2005, 2008). In addition, some studies have found that only specific aspects or components of ethnic identity exacerbate the effects of perceived 
discrimination, although these findings are also mixed. For example, the affective component of ethnic identity (i.e., pride in one's ethnic group) exacerbated the relationship between perceived discrimination and depressive symptoms for Korean American emerging adults (Lee, 2005), whereas the cognitive component of ethnic identity (i.e., a sense of clarity about one's ethnic group membership) exacerbated the association between peer discrimination and self-esteem for Asian American adolescents (Greene et al., 2006). In a recent meta-analysis, Pascoe and Smart Richman (2009) identified fifteen studies examining group identification as a moderator of the perceived discrimination-health relationship, yielding 68 tests of this hypothesis. Only $18 \%$ of the analyses were consistent with a buffering effect, $12 \%$ pointed to group identification as a risk factor. Most (71\%) analyses showed no moderating effect of group identification. The authors concluded that increasing levels of group identification "may be as likely to serve as a buffer than as an intensifier of the relationship between perceived discrimination and mental health" ( $p$. 543).

One possible explanation for these null findings is that when ethnic identification alone is being examined, important additional sources of variations are neglected. Here, we discuss the potentially crucial role of differences in the extent to which individuals identify with their national group, another essential component of self-concept for many ethnic minority group members (Berry et al., 2006; Phinney \& Devich-Navarro, 1997). In the present context, we conceptualize national identification as the extent to which an individual identifies with and feels a sense of belonging to the mainstream, dominant White/European American culture in which he or she lives.

Contemporary models of acculturation suggest that ethnic and national identifications are two relatively independent dimensions of identity for ethnic minority group members (Berry et 
al., 2006). Despite the fact that most ethnic minority group members also identify with the larger national (i.e., mainstream American) group, there is very little empirical research on the role of national identification in the perceived discrimination-psychological distress relationship. A longitudinal study focusing on immigrants in Finland coming from the former Soviet Union showed that perceived discrimination resulted in national disidentification, which in turn intensified hostility toward native Finns (Jasinskaja-Lahti, Liebkind, \& Solheim, 2009). In this case, national identification is a mediating factor, consistent with the rejection-identification model (Branscombe et al., 1999). To our knowledge, the extent to which national identification moderates the perceived discrimination-psychological distress relationship has not been tested.

Yet, there is empirical evidence that dual identification (strong ethnic and national identifications) may be beneficial for ethnic minority group members, and acculturation and social identity theories suggest that these benefits may extend to dealing with discrimination. For instance, in a study of immigrant youth in 13 Western settlement countries, youth who reported having a clear sense of their heritage cultural identity while establishing close ties with the larger national society were the best adjusted psychologically (i.e., higher life satisfaction and selfesteem, fewer psychological problems) and socioculturally (i.e., better school adjustment, fewer behavioral problems), as compared to the other identification patterns (Berry et al., 2006). Similarly, a meta-analysis by Nguyen and Benet-Martínez (in press) found that biculturalism (which includes dual identification) was strongly and positively correlated with better psychological and sociocultural adjustment across more than 80 studies and 23,000 participants.

Ideas from acculturation and social identity theories may shed light on why dual identification might be beneficial for ethnic minority group members. Acculturation theorists propose that dual identification is beneficial because it provides individuals with the resources to 
deal with life stressors, such as ethnic or racial discrimination, and that these benefits extend beyond the additive effects of ethnic and national identifications. In other words, the combination of ethnic and national identifications is uniquely valuable, and it leads to benefits in all areas of life (e.g., Berry et al., 2006; Phinney et al., 2001). More specifically and relevant to our study, dually identified individuals are likely to be competent in navigating through both ethnic and national groups (LaFromboise, Coleman, \& Gerton, 1993), and they tend to have social support networks from both groups (Mok, Morris, Benet-Martínez, \& KarakitapoğluAygün, 2007), which may be useful in dealing with life stressors. Therefore, individuals who strongly identify as both Asian and American should be able to deal better with discrimination due to the additional interpersonal or social resources afforded by this identity configuration.

Focusing more on the socio-cognitive benefits of dual identification, social identity theorists propose that individuals identify with groups to increase their self-esteem and decrease ambiguity in their social environments (Hogg \& Abrams, 1993; Tajfel \& Turner, 1986). In their integrative model of intergroup relations, Hornsey and Hogg (2000) propose that dual categorization (simultaneous activation of superordinate — national—and subgroup — ethnic — identities) is beneficial when the superordinate identity is a source of positive identity that does not conflict with cherished, emotionally significant subgroup identities. Although this model focuses on the consequences of dual identification for intergroup relations, it can be applied to the study of perceived discrimination and psychological distress, such that individuals are best able to cope with discrimination when they are connected to their ethnic group and simultaneously place this ethnic identification within the larger context of a more inclusive national group. Dual identification can enhance self-esteem, and when confronted with discriminatory experiences, these individuals have access to protective messages from both 
groups. For example, ethnic group membership can help people to attribute negative outcomes to ethnic or racial discrimination rather than to personal inadequacies, thereby protecting their wellbeing (Major \& Sawyer, 2009). At the same time, national group membership not only connects individuals to a positive social identity, it also makes them feel embedded within the larger social context, which is beneficial especially for low-status group members (Hornsey \& Hogg, 2000). In sum, dual identification may provide ethnic minority group members with the psychological and social resources to cope with and to challenge the discrimination that they experience. From this perspective, dual identification buffers individuals from the negative effects of discrimination.

In contrast, other identity configurations are less likely to have protective properties. First, individuals who display a strong ethnic identification but a weak national identification may have the psychological and social resources to deal with discrimination and/or be able to attribute negative outcomes to discrimination, which protects well-being, but they also may feel marginalized from the national identity, which harms well-being. This identity configuration also may exacerbate the effects of discrimination because people who strongly identify with their ethnic group are more likely to report racial discrimination and to react negatively to discrimination (McCoy \& Major, 2003; Operario \& Fiske, 2001), to be more vigilant for discrimination incidents (Barrett \& Swim, 1998), or to be more sensitive to rejection in the form of racial discrimination (Downey \& Feldman, 1996). This heightened sensitivity combined with more acute emotional responses may increase vulnerability to racial discrimination, resulting in greater psychological distress. Second, individuals who display a weak ethnic identification but a strong national identification may lack the important psychological and social resources stemming from ethnic group identification, which in turn may make attachment to the national 
group a risk factor, especially if discrimination comes from dominant, mainstream group members. Finally, the case of individuals who weakly identify with their ethnic and national groups might be more straightforward because, relatively speaking, these individuals likely lack resources to maintain or protect their well-being when experiencing discrimination. They are prone to experience these situations as acute stressors because they do not possess a frame of reference that would allow them to discount discrimination as unfair and cannot mobilize the psychological and social resources instrumental to coping with negative treatment.

In summary, we propose that both ethnic and national group identifications should be examined as moderators of the perceived discrimination-psychological distress relationship. Rather than considering these identifications as independent sources of variations, it is important to examine the interactive effect of ethnic and national identifications to better understand how group identification can buffer the negative effects of perceived discrimination. Based on previous research, we hypothesized that more frequent perceived discrimination would be related to higher psychological distress. We did not expect either ethnic or national identification alone to moderate this relationship. However, based on reasons outlined above, we hypothesized that the perceived discrimination-psychological distress relationship would differ as a function of the configuration of ethnic and national identifications displayed by Asian Americans. Specifically, we expected that this relationship would be weaker among those strongly identified with both their ethnic and national groups (dual identification) compared to other identification patterns. This perspective should provide a more nuanced approach to the role of group identification. In line with a growing body of work (Crabtree, Haslam, Postmes, \& Haslam, 2010), it is likely to bring to the fore the fact that group identifications have both positive and negative implications. In some cases, group identifications may have protective properties, but in other cases they may 
do little to deflect, and may even intensify, the repercussions of discrimination on well-being.

\section{Method}

\section{Participants and Procedure}

Participants were 259 Asian American undergraduate students from a large public university on the west coast of the United States. Half of the sample (128 or 49.4\%) selfidentified as Filipino American, with the other half self-identifying either as a different Asian American subgroup or as Asian/Asian American (results reported below did not change substantively when Filipino and other Asian participants were examined separately). Participants were between 18 to 26 years of age $(M=18.69, S D=1.24)$, two-thirds of the sample (172 or $66.4 \%$ ) were in their freshman year, and most (174 or $67.2 \%)$ were women. The majority (201 or $78.3 \%$ ) of participants were born in the United States, and all were U.S. citizens.

Participants were recruited through advertisements in the daily campus newspaper (paid) and the psychology department subject pool (unpaid) for a larger study on perceived discrimination. Paid respondents were given $\$ 15$, and subject pool respondents received partial credit for an introductory psychology course for their participation. All participants completed the study on a computer running Inquisit 2.0 software (Draine, 2005) in small groups of up to 4 people. Computers were located in cubicles in a small lab-setting, and there were screens between each computer desk for privacy. The measures reported here were administered in the following order: perceived discrimination, psychological distress (randomizing the order of anxiety symptoms, depression symptoms, and CES-D measures), and group identification (randomizing the order of the ethnic and national identification measures).

\section{Measures}

Perceived discrimination. The Schedule of Racist Events (SRE; Landrine \& Klonoff, 
1996) consists of 17 items assessing the frequency of specific experiences of racial discrimination. The SRE has been adapted successfully to capture discrimination experiences among Asian Americans (Liang, Li, \& Kim, 2004), and in previous studies, scores on the SRE have been significantly correlated with a variety of indicators of psychological distress, including anxiety and depression (Fischer \& Shaw, 1999; Huynh, Devos, \& Dunbar, 2012; Klonoff \& Landrine, 1999; Klonoff, Landrine, \& Ullman, 1999; Landrine \& Klonoff, 1996). Respondents rated the frequency of each event during the past year on a 6-point Likert-type scale with the following response options: $1=$ never, 2 = once in a while (less than $10 \%$ of the time), $3=$ sometimes $(10 \%-25 \%$ of the time $), 4=$ a lot $(26 \%-49 \%$ of the time $), 5=$ most of the time $(50 \%$ $70 \%$ of the time), or $6=$ almost all of the time (more than $70 \%$ of the time). A sample item was, "How many times in the past year have you been treated unfairly by your coworkers, fellow students and colleagues because you are [ethnic identity response]?" Before responding to the SRE items, participants answered an open-ended question about their ethnic identity. This answer (e.g., "Asian American," "Filipino American," "Korean American," or “Asian”) was piped into the SRE items by the software program so that each item reflected the participant's own label for his/her ethnic identity. Principle axis factoring indicated that the SRE items loaded on one factor (all items had loadings $\geq .30$ except for an item regarding how often participants were forced to take drastic steps to deal with a discriminatory experience). We retained this item because it did not significantly change score reliability, and the regression results below did not change substantively when the item was excluded. Higher mean SRE scores indicate more frequent perceived discrimination.

Anxiety symptoms. Participants rated the extent to which they experienced anxiety symptoms within the past week (including the day of the study) on a 4-point Likert-type scale, 
ranging from $1=$ rarely or none of the time-less than 1 day to $4=$ most of the time -5 to 7 days. As part of the larger study, participants also completed two Implicit Association Tests (IATs; Greenwald, McGhee, \& Schwartz, 1998) that assessed the strength of association between the self and the concepts depressed (vs. happy) and anxious (vs. calm); therefore, we administered the same anxiety and depression items used in the IATs at the explicit, self-report level, which is reported here. For anxiety, 14 items (7 anxiety, 7 calm [reverse-scored]) were selected based on a review of the literature (Antony, Orsillo, \& Roemer, 2001) so that the most common dimensions of anxiety measurement were represented: control over emotions, control over cognitions, ability to relax, startle response or hyperarousability, worrying, apprehension, restlessness, fears, and somatic symptoms. Principle axis factoring indicated that the 14 anxiety symptoms loaded on one factor. Higher mean scores indicate more frequent anxiety symptoms.

Depression symptoms. Participants rated the extent to which they experienced depression symptoms within the past week (including the day of the study) on the same 4-point Likert-type scale. Based on a review of the literature (Nezu, Ronan, Meadows, \& McClure, 2000), we chose 14 items (7 depression, 7 happiness [reverse-scored]) to represent the most common dimensions of depression measurement: depressed mood, guilt, suicidal thoughts, lack of interest, psychomotor retardation, insomnia/sleep disturbances, somatic symptoms, and agitation. Principle axis factoring indicated that the 14 depression symptoms loaded on one factor. Higher mean scores indicate more frequent depression symptoms.

In addition, participants completed another measure of depression symptoms: the Center for Epidemiologic Studies Depression scale (CES-D; Radloff, 1977), a widely-used 20-item measure that assesses the presence and frequency of clinical symptoms associated with depression (for a review, see Eaton, Muntaner, Smith, Tien, \& Ybarra, 2004). Participants rated 
the frequency with which the symptoms had occurred over the past week on the same 4-point Likert-type scale described above. Sample items included "I felt depressed" and "I had trouble keeping my mind on what I was doing." Principle axis factoring indicated that 18 out of 20 CESD items loaded on one factor, and the remaining 2 items did not load on any factor. However, these items were retained because they did not change score reliability, and the regression results below did not change substantively when they were excluded. Higher mean CES-D scores indicate more frequent depression symptoms. As indicated in the Results section below, the two measures of anxiety and depression, which we created based on literature reviews, were correlated, as expected, with each other and with the CES-D, a well-established measure of depression symptoms. Thus, we were confident that items selected did indeed measured anxiety and depression symptoms as intended.

Group identification. We measured ethnic and national identifications using two different scales. First, to measure ethnic identification and sense of belonging, we used the Multigroup Ethnic Identity Measure (MEIM; Phinney, 1992). This is a widely-used measure of ethnic identity, and it was developed purposefully for use with various ethnic groups and across different national contexts (Berry et al., 2006; Phinney \& Ong, 2007). The MEIM consists of 12 items rated on a 5-point Likert-type scale ranging from $1=$ strongly disagree to $5=$ strongly agree. A sample item was, "I have a lot of pride in my [ethnic identity response] group." As with the SRE items, each participant's answer about his/her ethnic identity was piped into the MEIM items by the software program. Principle axis factoring indicated that the 12 items loaded on one factor. Higher mean scores indicate stronger ethnic identification.

To measure national identification and sense of belonging to the mainstream American culture, we used the Mainstream Comfort subscale (6 items) from the Scale of Ethnic Experience 
(SEE, Malcarne, Chavira, Fernandez, \& Liu, 2006). The SEE was developed and tested in 5 studies with more than 3,800 participants from 4 different ethnic groups (Black/African Americans, White/European Americans, Filipino Americans, and Mexican Americans). The factor structure of the SEE was confirmed across these 4 ethnic groups, and there was evidence of concurrent validity with measures of ethnic identity and acculturation (see Malcarne et al. for more details about development and validation). The Mainstream Comfort items administered in the present study were rated on a 5-point Likert-type scale ranging from $1=$ strongly disagree to 5 = strongly agree. A sample item was, "I feel like I belong to mainstream American culture." Principle axis factoring indicated that the 6 items loaded on one factor. Higher mean scores indicate stronger national identification.

\section{Results}

\section{Descriptive Statistics}

Means, standard deviations, Cronbach's alphas, and correlations for all measured variables appear in Table 1. In general, participants did not report experiencing discrimination extremely frequently. However, they experienced a non-trivial amount of discrimination on average $(M=2.48, S D=0.53)$, or between once in a while and sometimes or $10 \%-25 \%$ of the time. In other words, participants reported experiencing discrimination based on their race or ethnicity up to a quarter of the time within the past year. The type of discrimination that participants reported experiencing most frequently was "wanting to tell someone off for being racist but didn't say anything." There were no reliable gender, generational (immigrant vs. nonimmigrant), or ethnic group (Filipino vs. non-Filipino Asians) differences on reported frequency of discrimination. Therefore, we did not control for these demographic variables in the regression analyses reported below. 
Overall, perceived discrimination was the only variable consistently related to psychological distress $(.24<r s<.33, p \mathrm{~s}<.001)$. The small-moderate positive relationships between perceived discrimination and psychological distress are consistent with previous research in this area (Pascoe \& Smart Richman, 2009). Also consistent with prior research (e.g., Berry et al., 2006), the two dimensions of group identity (ethnic and national identifications) were relatively independent. In addition, group identifications were neither related to perceiving discrimination nor to psychological distress (with one exception). Finally, the three indicators of psychological distress (anxiety symptoms, depression symptoms, and CES-D) were highly intercorrelated $(.69<r s<.82, p s<.001)$. Thus, we computed an aggregate psychological distress score (see Table 1 for mean, standard deviation, and correlations) using these three scales, and this score was the main dependent variable in the following regression analyses.

\section{Group Identifications as Moderators of the Perceived Discrimination-Psychological}

\section{Distress Relationship}

We used a three-step hierarchical multiple regression analysis to test our hypothesis regarding the moderating role of group identifications. Per the recommendations of Aiken and West (1991), we mean-centered perceived discrimination, ethnic identification, and national identification, and computed interaction terms by multiplying the appropriate variables. We entered the main effects in the first step of the analysis, followed by the two-way interactions in step 2, and finally the three-way interaction in step 3 (see Table 2 for full regression results).

As expected, there was a medium and significant positive main effect of perceived discrimination on aggregated psychological distress, $\beta=.29, t(255)=4.84, p<.001$. When each measure of psychological distress was examined separately in regression analyses, a similar pattern of results was found although not all $\beta$ s reached significance (see Table 2). There were no 
significant main effects of ethnic or national identification, or significant two-way interactions in any regression model testing our hypothesis. More importantly, the main effect of perceived discrimination was qualified by a significant three-way interaction of perceived discrimination $x$ ethnic identification $\times$ national identification on aggregated psychological distress, $\beta=-.26$, $t(251)=-2.21, p=.03$ (see Figure 1). Simple-slope analyses indicated that the relationship between perceived discrimination and aggregated psychological distress was significantly different at various levels of ethnic and national identifications. For the dual identification group, perceived discrimination did not predict aggregated psychological distress $(b=0.09, t=0.70, p=$ .49). In contrast, for the group with weak ethnic/strong national identifications, perceived discrimination predicted aggregated psychological distress $(b=0.47, t=3.74, p=.0002)$. For the remaining two groups [strong ethnic/weak national identifications $(b=0.30, t=3.10, p=.002)$ and weak ethnic/weak national identifications $(b=0.26, t=3.22, p=.001)]$, the relationship between perceived discrimination and aggregated psychological distress was significant but more moderate. In other words, the pattern of results is consistent with the notion that a dual identification has a buffering effect on psychological distress, whereas group identification could be conceptualized as a risk factor for those in the weak ethnic/strong national identification group. This interaction pattern (along with analyses performed separately for anxiety, depression, and CES-D that painted a similar picture) is consistent with our assertion that the moderating effects of group identification on the perceived discrimination-psychological distress relationship are best understood when both ethnic and national identifications are simultaneously and interactively considered.

\section{Discussion}

The goal of the present research was to examine the potential moderating role of ethnic 
and national identifications on the relationship between perceived discrimination and psychological distress. Our theoretical framework led us to distinguish four identification patterns and to hypothesize that dual identification (strong ethnic and national identifications) would have protective properties, and therefore be characterized by the weakest relationship between perceived discrimination and psychological distress.

Before we discuss evidence for this hypothesis, it is worth stressing that perceived discrimination is consistently linked to psychological distress: as perceived discrimination increases, report of anxiety and depression symptoms increases as well. This finding is in line with a solid body of research (Gee et al., 2007; Greene et al., 2006; Pascoe \& Smart Richman, 2009; Romero et al., 2007), but given the paucity of research on experiences of discrimination among Asian Americans as compared to other ethnic groups, providing evidence for this relationship with a sample of educated and acclimated U.S. citizens of Asian ancestry is an important prerequisite step to address our more specific research aim.

Evaluating potential moderating variables for this perceived discriminationpsychological distress relationship helps to identify protective factors. However, examination of ethnic or national identification alone does not provide full understanding of the potentially protective nature of group identification. In contrast, critical insights are gained when these two important facets of the self-concept of Asian Americans are simultaneously considered. More precisely, the interconnections between ethnic and national identifications are sources of reliable variations in the extent to which experiencing racial discrimination is linked to self-reported anxiety and depression symptoms. As predicted, the relationship between perceived discrimination and psychological distress is consistently weaker for individuals who display a dual identification. For those with weak ethnic identification combined with strong national 
identification, the opposite is true: the strongest relationship between perceived discrimination and psychological distress is obtained for this configuration. The relationship is more moderate for individuals with weak national identification whether it is accompanied by weak or strong ethnic identification. To better understand this complex pattern, it is worth considering the identity configurations that yielded the two most extreme associations between perceived discrimination and psychological distress.

Individuals with a dual identification pattern display the weakest relationship between perceived discrimination and psychological distress. Thus, there appears to be benefits associated with this identity configuration. People who possibly cope the best with discrimination (thereby reporting the least psychological distress) are those who are connected to their ethnic group and simultaneously place this identification within the larger context of the national group. At the level of their self-image, there can be some sense of unity between more or less inclusive selfdefinitions, and the presence of one identification may enrich the other. When confronted with discriminatory experiences, these individuals have access to protective messages originating from both groups. Ethnic identification may allow them to appraise these experiences as reflecting discrimination based on ethnic or racial distinctions rather than personal inadequacies. Meanwhile, attachment to the national group can prevent them from feeling marginalized from the larger social context, reminding them that their relation to the national group cannot be reduced to these discriminatory experiences. Thus, this identification pattern has protective factors built into its very structure.

In contrast, strong national identification without strong ethnic identification appears to be devoid of protective properties and even harbor psychological risks. Without the symbolic and social resources stemming from ethnic identification, these individuals are less able to attribute 
negative, discriminatory experiences to unfair treatment based on their ethnic group membership, which would protect well-being, and more likely to attribute them to personal limitations, which may result in increased psychological distress (Major \& Sawyer, 2009). In addition, the increased affiliation with the national group may serve as a risk factor. To a large extent, discrimination can be seen as originating from the national group and is essentially a message of rejection (Smart Richman \& Leary, 2009). Therefore, individuals with this identification pattern may experience more psychological distress when they perceive rejection from the national group in the form of racial discrimination. Lacking attachment to the ethnic group, they may assume they are at fault for unfavorable outcomes, and deem this message significant because they highly value membership in the national group.

The remaining two identity configurations do not seem to operate either as buffering factors or as risk factors. The fact that, for individuals who weakly identify with the national group, a strong or weak ethnic identification does not translate into a different relationship between perceived discrimination and psychological distress illustrates the limitations of an approach that would focus on a single source of social identity, namely ethnic identity. The potential benefits or costs of ethnic identification come to the forefront when considering whether it is coupled with a strong or weak attachment to the national group.

Several limitations of the present study and avenues for future research need to be discussed. First, this study was limited to Asian American college students on the west coast of the United States. Future research should examine the extent to which ethnic and national identifications yield similar effects for Asian American samples that differ from this sample on variables such as age, education, socio-economic status, or social context. The findings of a nationally representative study of mental health among Asian Americans already suggest that the 
role of ethnic identity (as a protective vs. risk factor) differs as a function of age and immigration status (Yip, Gee, \& Takeuchi, 2008). In addition, it would be informative to examine whether contextual variables, such as geographical location, ethnic density of respondents' neighborhood or city, the availability of ethnic institutions such as Chinatowns or community centers, influence the strength and meaning of identification with the ethnic and national groups. Variations in these contextual variables may have implications for the role that group identification plays in the perceived discrimination-psychological distress relationship. For instance, Asian Americans living in the midwest, as compared to those living on the west coast, are likely to have fewer ethnic resources in their environment, which in turn may make them rely more heavily on their affiliation with the national group to meet important motives such as a sense of belonging, selfunderstanding, or self-esteem. Thus, rejection from the national group in the form of ethnic discrimination may be more detrimental for these individuals. In addition to examining variations among Asian Americans, investigations should be extended to other ethnic minority groups and to groups experiencing discrimination based on other identity dimensions (e.g., gender, sexual orientation, religion, or socio-economic status). At the conceptual level, one may assume that group identifications would operate similarly, but important distinctions and specificities also are likely to emerge. Further investigations also would benefit from distinguishing various components of group identification. Group identification is a multidimensional construct extending beyond the importance of group membership to the self (Ashmore, Deaux, \& McLaughlin-Volpe, 2004). For example, one may highly identify with a group and simultaneously hold it in low esteem (Sellers \& Shelton, 2003). Specific components of group identification need to be disentangled to better understand the phenomenological experience of group identification and the aspects of such identification that may prove to be 
relatively beneficial or detrimental in dealing with discriminatory experiences.

Another limitation of the present study is inherent in the self-report nature of the data. Various cognitive and motivational biases may shape the extent to which individuals express strong or weak attachment to their groups, are able or willing to report the occurrence of discrimination or of anxiety and depression symptoms. Despite the limitations of self-report measures, the present data revealed important interconnections among group identifications, perceived discrimination, and psychological distress. Finally, we should stress that our findings are strictly correlational. The cross-sectional design does not allow us to establish causal pathways among the constructs assessed. The pattern obtained is consistent with the notion that dual identification has a buffering effect on the adverse effects of perceived discrimination, but longitudinal data would be needed to establish this firmly. Previous longitudinal studies have established that increased perceived discrimination is a source of increased psychological distress (Sellers \& Shelton, 2003). However, the reverse may also be true. It is possible that individuals with higher levels of psychological distress are hyper-vigilant to discrimination, thus more likely to interpret ambiguous events as discriminatory (Chan \& Mendoza-Denton, 2008). Another layer of complexity is added when considering the role that ethnic and national identifications may play in these processes. Without a doubt, multiple causal pathways are likely to operate among the constructs of interest. Depending the circumstances, increasing or decreasing group identification also may function as coping mechanisms in the face of pervasive discrimination (Branscombe, Fernández, Gómez, \& Cronin, 2011). This being said, correlational studies, with all their limitations, are a useful step to draw attention to issues that have been neglected and to generate new hypotheses.

The fact that dual identification seems to be the most beneficial identity configuration for 
Asian American college students has some important implications. First, this finding is consistent with previous research on the benefits of dual identification for various ethnic groups in different countries (e.g., Berry et al., 2006; Nguyen and Benet-Martínez, in press), and together, this body of research suggests that dual identification should be encouraged and supported institutionally. Public policies that emphasize multiculturalism (vs. assimilation) may enable ethnic minority group members to maintain strong identification with their subgroup while also having a sense of belonging to the larger national group. The present findings suggest that this dual identification pattern may help them to better cope with ethnic or racial discrimination.

From a more conceptual and methodological point of view, the present study points to the fact that, when examining the extent to which group identifications operate as protective or risk factors, relying on a multi-group identification perspective is warranted and even necessary. In this study, when ethnic and national identification are examined separately, the role of group identification as a moderating variable is unclear. It is only when both of these constructs are analyzed simultaneously and interactively that evidence consistent with the notion that group identification can buffer individuals against the adverse effects of discrimination materializes. In previous research, when ethnic identification was measured alone, its role was largely ambiguous (Pascoe \& Smart Richman, 2009). Strong ethnic identification coupled with strong national identification is the configuration under which the perceived discrimination-psychological distress link is the weakest, consistent with a buffering effect. Thus, examining identity configurations is a fruitful approach to better understand how group identification may shape experiences of discrimination.

In sum, even among an educated sample of Asian American college students, a non- 
trivial frequency of racial discrimination is being reported. In addition, perceived discrimination is linked to self-reports of anxiety and depression symptoms. Understanding the circumstances under which this relationship is weakened is a challenge that has both practical and theoretical implications. Without overstating our findings, the present data point to the need to conceptualize and examine group identifications in a more complex manner than what has been done in the past. More precisely, understanding the nature and importance of ethnic and national identifications require considering their relationship. 


\section{References}

Aiken, L. S., \& West, S. G. (1991). Multiple regression: Testing and interpreting interactions. Newbury Park, CA: Sage.

Allport, G. W. (1954). The nature of prejudice. New York, NY: Doubleday Books.

Antony, M. M., Orsillo, S. M., \& Roemer, L. (Eds.) (2001). Practitioner's guide to empirically based measures of anxiety. New York, NY: Kluwer Academic/Plenum Publishers.

Ashmore, R. D., Deaux, K., \& McLaughlin-Volpe, T. (2004). An organizing framework for collective identity: Articulation and significance of multidimensionality. Psychological Bulletin, 130, 80-114.

Barrett, L. F., \& Swim, J. K. (1998). Appraisals of prejudice and discrimination. In J. K. Swim, \& C. S. Stangor (Eds.), Prejudice: The target's perspective (pp. 11-36). San Diego, CA: Academic Press.

Berry, J. W., Phinney, J. S., Sam, D. L., \& Vedder, P. (2006). Immigrant youth: Acculturation, identity, and adaptation. Applied Psychology: An International Review, 55, 303-332.

Branscombe, N.R., Fernández, S., Gómez, A., \& Cronin, T. (2011). Moving toward or away from a group identity: Different strategies for coping with pervasive discrimination. In J. Jetten, C. Haslam \& S. A. Haslam (Eds.), The social cure: Identity, health and well-being (pp. 115-131). New York: Psychology Press.

Branscombe, N. R., Schmitt, M. T. \& Harvey, R. D. (1999). Perceiving pervasive discrimination among African Americans: Implications for group identification and well-being. Journal of Personality and Social Psychology, 77, 135-149.

Cassidy, C., O’Connor, R. C., Howe, C., \& Warden, D. (2004). Perceived discrimination and psychological distress: The role of personal and ethnic self-esteem. Journal of 
Counseling Psychology, 51, 329-339

Chan, W., \& Mendoza-Denton, R. (2008). Status-based rejection sensitivity among Asian Americans: Implications for psychological distress. Journal of Personality, 76, 13171346.

Cheng, J. K. Y., Fancher, T. L., Ratanasen, M., Conner, K. R., Duberstein, P. R., Sue, S., \& Takeuchi, D. (2010). Lifetime suicidal ideation and suicide attempts in Asian Americans. Asian American Journal of Psychology, 1, 18-30.

Cheryan, S., \& Monin, B. (2005). “Where are you really from?”: Asian Americans and identity denial. Journal of Personality and Social Psychology, 89, 717-730.

Clark, R., Anderson, A., Clark, V. R., \& Williams, D. R. (1999). Racism as a stressor for African Americans: A biopsychosocial model. American Psychologist, 54, 805-816.

Crabtree, J. W., Haslam, S. A., Postmes, T., \& Haslam, C. (2010). Mental health support groups, stigma, and self-esteem: Positive and negative implications of group identification. Journal of Social Issues, 66, 553-569.

Crocker, J., \& Major, B. (1989). Social stigma and self-esteem: The self-protective properties of stigma. Psychological Review, 96, 608-630.

DuBois, D. L., Burk-Braxton, C., Swenson, L. P., Tevendale, H. D., \& Hardesty, J. L. (2002). Race and gender influences on adjustment in early adolescence: Investigation of an integrative model. Child Development, 73, 1573-1592.

Draine, S. C. (2005). Inquisit 2.0 [Computer Software]. Seattle, WA: Millisecond Software.

Eaton, W. W., Muntaner, C., Smith, C., Tien, A., \& Ybarra, M. ( 2004). Center for Epidemiologic Studies Depression Scale: Review and revision (CESD and CESD-R). In M. E. Maruish (Ed.), The use of psychological testing for treatment planning and 
outcomes assessment (3rd Ed., pp. 363-377). Mahwah, NJ: Lawrence Erlbaum.

Fischer, A. R. \& Shaw, C. M. (1999). African Americans' mental health and perceptions of racist discrimination: The moderating effects of racial socialization experiences and selfesteem. Journal of Counseling Psychology, 46, 395-407.

Gee, G. C., Spencer, M., Chen, J., Yip, T., \& Takeuchi, D. T. (2007). The association between self-reported racial discrimination and 12-month DSM-IV mental disorders among Asian Americans nationwide. Social Science and Medicine, 64, 1984-1996.

Goto, S. G., Gee, G. C., \& Takeuchi, D. T. (2002). Strangers still? The experience of discrimination among Chinese Americans. Journal of Community Psychology, 30, 211224.

Greene, M. L., Way, N., \& Pahl, K. (2006). Trajectories of perceived adult and peer discrimination among Black, Latino, and Asian American adolescents: Patterns and psychological correlates. Developmental Psychology, 42, 218-238.

Greenwald, A. G., McGhee, D. E., \& Schwartz, J. L. K. (1998). Measuring individual differences in implicit cognition: The implicit association test. Journal of Personality and Social Psychology, 74, 1464-1480.

Hahm, H. C., Ozonoff, A., Gaumond, J., \& Sue, S. (2010). Perceived discrimination and health outcomes: A gender comparison among Asian-Americans nationwide. Women's Health Issues, 20, 350-358.

Harrell, S. P. (2000). A multidimensional conceptualization of racism-related stress: Implications for the well-being of people of color. American Journal of Orthopsychiatry, 70, 42-57.

Hogg, M. A., \& Abrams, D. (1993). Towards a single-process uncertainty-reduction model of social motivation in groups. In M. A. Hogg \& D. Abrams (Eds.), Group motivation: 
Social psychological perspectives (pp. 173-190). Hemel Hempstead, England: Harvester Wheatsheaf.

Hornsey, M. J., \& Hogg, M. A. (2000). Assimilation and diversity: An integrative model of subgroup relations. Personality and Social Psychology Review, 4, 143-156.

Huynh, Q.-L., Devos, T., \& Dunbar, C. M. (2012). The psychological costs of painless but recurring experiences of racial discrimination. Cultural Diversity and Ethnic Minority Psychology, 18, 26-34.

Huynh, Q.-L., Devos, T., \& Smalarz, L. (2011). Perpetual foreigner in one's own land: Potential implications for identity and psychological adjustment. Journal of Social and Clinical Psychology, 30, 133-162.

Jasinskaja-Lahti, I., Liebkind, K., \& Solheim, E. (2009). To identify or not to identify? National disidentification as an alternative reaction to perceived ethnic discrimination. Applied Psychology: An International Review, 58, 105-128.

Klonoff, E. A. \& Landrine, H. (1999). Cross-validation of the Schedule of Racist Events. Journal of Black Psychology, 25, 231-254.

Klonoff, E. A., Landrine, H., \& Ullman, J. B. (1999). Racial Discrimination and psychiatric symptoms among Blacks. Cultural Diversity and Ethnic Minority Psychology, 5, 329339.

LaFromboise, T., Coleman, H. L., \& Gerton, J. (1993). Psychological impact of biculturalism: Evidence and theory. Psychological Bulletin, 114, 395-412.

Landrine, H., \& Klonoff, E. A. (1996). The Schedule of Racist Events: A measure of racist discrimination and a study of its negative physical and mental health consequences. Journal of Black Psychology, 22, 144-168. 
Liang, C. T. H., Li, L. C. \& Kim, B. S. K. (2004). The Asian American racism-related stress inventory: Development, factor analysis, reliability, and validity. Journal of Counseling Psychology, 51, 103-114.

Malcarne, V., Chavira, D., Fernandez, S., \& Liu, P. (2006). The scale of ethnic experience: Development and psychometric properties. Journal of Personality Assessment, 86, 150161.

Major, B., \& Sawyer, P. J. (2009). Attributions to discrimination: Antecedents and consequences. In T. D. Nelson (Ed.), Handbook of prejudice, stereotyping, and discrimination (pp. 89-110). New York, NY: Psychology Press.

McCoy, S. K., \& Major, B. (2003). Group identification moderates emotional responses to perceived prejudice. Personality and Social Psychology Bulletin, 29, 1005-1017.

Mok, A., Morris, M., Benet-Martínez, V., \& Karakitapoğlu-Aygün, Z. (2007). Embracing American culture: Structures of social identity and social networks among firstgeneration biculturals. Journal of Cross-Cultural Psychology, 38, 629-635.

Mossakowski, K. N. (2003). Coping with perceived discrimination: Does ethnic identity protect mental health? Journal of Health and Social Behavior, 44, 318-331.

Nezu, A. M., Ronan, G. F., Meadows, E. A., \& McClure, K. S. (2000). Practitioner's guide to empirically based measures of depression. New York, NY: Kluwer Academic/Plenum Publishers.

Nguyen, A.-M. D., \& Benet-Martínez, V. (2010). Multicultural identity: What it is and why it matters. In R. J. Crisp (Ed.), The psychology of social and cultural diversity (pp. 87-114). West Sussex, UK: Wiley-Blackwell.

Nguyen, A.-M. D., \& Benet-Martínez, V. (in press). Biculturalism and adjustment: A meta- 
analysis. Journal of Cross-Cultural Psychology.

Noh, S., Beiser, M., Kaspar, V., Hou, F., \& Rummens, J. (1999). Perceived racial discrimination, depression, and coping: A study of Southeast Asian refugees in Canada. Journal of Health and Social Behavior, 40, 193-207.

Nolen-Hoeksema, S., Larson, J., \& Grayson, C. (1999). Explaining the gender difference in depressive symptoms. Journal of Personality and Social Psychology, 77, 1061-1072.

Operario, D., \& Fiske, S. T. (2001). Ethnic identity moderates perceptions of prejudice: Judgments of personal versus group discrimination and subtle versus blatant bias. Personality and Social Psychology Bulletin, 27, 550-561.

Pascoe, E. A., \& Smart Richman, L. (2009). Perceived discrimination and health: A metaanalytic review. Psychological Bulletin, 135, 531-554.

Perlow, H. M., Danoff-Burg, S., Swenson, R. R., \& Pulgiano, D. (2004). The impact of ecological risk and perceived discrimination on the psychological adjustment of African American and European youth. Journal of Community Psychology, 32, 375-389.

Phinney, J. S. (1992). The multigroup ethnic identity measure: A new scale for use with diverse groups. Journal of Adolescent Research, 7, 156-176.

Phinney, J. S., \& Devich-Navarro, M. (1997). Variations in bicultural identification among African American and Mexican American adolescents. Journal of Research on Adolescence, 7, 3-32.

Phinney, J. S., \& Ong, A. D. (2007). Conceptualization and measurement of ethnic identity: Current status and future directions. Journal of Counseling Psychology, 54, 271-281.

Radloff, L. S. (1977). The CES-D scale: A self-report depression scale for research in the general population. Applied Psychological Measurement, 1, 385-401. 
Romero, A. J., Carvajal, S. C., Volle, F., \& Orduña, M. (2007). Adolescent bicultural stress and its impact on mental well-being among Latinos, Asian Americans, and European Americans. Journal of Community Psychology, 35, 519-534.

Sellers, R. M., \& Shelton, J. N. (2003). The role of racial identity in perceived racial discrimination. Journal of Personality and Social Psychology, 84, 1079-1092.

Smart Richman, L., \& Leary, M. R. (2009). Reactions to discrimination, stigmatization, ostracism, and other forms of interpersonal rejection: A multimotive model. Psychological Review, 116, 365-383.

Steele, C. M., Spencer, S. J., \& Aronson, J. (2002). Contending with group image: The psychology of stereotype and social identity threat. In M. P. Zanna (Ed.), Advances in experimental social psychology (Vol. 34, pp. 379-440). San Diego, CA: Academic Press.

Sue, D. W., Capodilupo, C. M., Torino, G. C., Bucceri, J. M., Holder, A. M. B., Nadal, K. L., \& Esquilin, M. (2007). Racial microaggressions in everyday life: Implications for clinical practice. American Psychologist, 62, 271-286.

Syed, M., \& Juan, M. J. D. (2012). Discrimination and psychological distress: Examining the moderating role of social context in a nationally representative sample of Asian American adults. Asian American Journal of Psychology, 3, 104-120.

Tajfel, H., \& Turner, J. C. (1986). The social identity theory of intergroup behaviour. In S. G. Worschel \& W. Austin (Eds.), Psychology of intergroup relations (pp. 7-24). Chicago, IL: Nelson-Hall.

Takaki, R. (1998). A larger memory: A history of our diversity, with voices. Boston, MA: Little, Brown and Company.

U.S. Department of Health and Human Services (2001). Mental health: Culture, race, and 
ethnicity-A supplement to Mental health: A report of the surgeon general. Rockville, MD: U.S. Department of Health and Human Services, Substance Abuse and Mental Health Services Administration, Center for Mental Health Services. Retrieved from http://download.ncadi.samhsa.gov/ken/pdf/SMA-01-3613/sma-01-3613.pdf

Williams, D. R., Spencer, M. S., \& Jackson, J. S. (1999). Race, stress and physical health: The role of group identity. In R. J. Contrada \& R. D. Ashmore (Eds.), Self and identity: Fundamental issues (pp. 71-100). New York: Oxford University Press.

Yip, T., Gee, G. C., \& Takeuchi, D. T. (2008). Racial discrimination and psychological distress: The impact of ethnic identity and age among immigrant and United States-born Asian adults. Developmental Psychology, 44, 787-800.

Yoo, H. C., \& Lee, R. M. (2005). Ethnic identity and approach-type coping as moderators of the racial discrimination/well-being relation in Asian Americans. Journal of Counseling Psychology, 52, 497-506.

Yoo, H. C., \& Lee, R. M. (2008). Does ethnic identity buffer or exacerbate the effects of frequent racial discrimination on situational well-being of Asian Americans? Journal of Counseling Psychology, 55, 63-74. 
Table 1

Descriptive Statistics, Cronbach's Alphas, and Correlations among Measured Variables

\begin{tabular}{|c|c|c|c|c|c|c|c|c|c|}
\hline & $M$ & $S D$ & Discrimination & Ethnic & National & Anxiety & Depression & CES-D & Distress \\
\hline Perceived Discrimination & 2.45 & .45 & $(.86)$ & & & & & & \\
\hline Ethnic Identification & 3.82 & .67 & -.04 & $(.91)$ & & & & & \\
\hline National Identification & 3.22 & .61 & -.07 & -.05 & $(.79)$ & & & & \\
\hline Anxiety Symptoms & 2.03 & .51 & $.26 * * *$ & -.06 & -.03 & $(.88)$ & & & \\
\hline Depression Symptoms & 1.74 & .50 & $.24 * * *$ & -.10 & $-.14^{*}$ & $.74 * * *$ & $(.90)$ & & \\
\hline CES-Depression & 1.76 & .45 & $.33 * * *$ & -.11 & -.10 & $.69 * * *$ & $.82 * * *$ & $(.89)$ & \\
\hline Aggregated Psychological Distress & 1.84 & .45 & $.30 * * *$ & -.10 & -.10 & $.89 * * *$ & $.94 * * *$ & $.91 * * *$ & $(.90)$ \\
\hline
\end{tabular}

Note. Values in the diagonal are Cronbach's alpha. ${ }^{*} p<.05 . * * p<.01 . * * * p<.001$. Discrimination = Perceived discrimination;

Ethnic $=$ ethnic identification; National $=$ national identification; Anxiety $=$ anxiety symptoms; Depression $=$ depression symptoms;

CES-D = CES-Depression; Distress = Aggregated psychological distress. 
Table 2

Hierarchical Multiple Regression Analyses Predicting Psychological Distress Outcomes from Perceived Discrimination, Ethnic Identification, and National Identification

\begin{tabular}{|c|c|c|c|c|c|}
\hline Criterion Variable & $\beta$ & $t$ & $p$ & $\Delta R^{2}$ & $p$ \\
\hline \multicolumn{6}{|l|}{ Aggregated Psychological Distress } \\
\hline Discrimination & .29 & 4.84 & $<.001$ & .10 & $<.001$ \\
\hline Ethnic & -.09 & -1.52 & .13 & & \\
\hline National & -.07 & -1.13 & .26 & & \\
\hline Discrimination $\times$ Ethnic & -.03 & -1.24 & .22 & .01 & .43 \\
\hline Discrimination $\times$ National & .02 & 0.77 & .44 & & \\
\hline Ethnic $\times$ National & .02 & 0.81 & .42 & & \\
\hline Discrimination $\times$ Ethnic $\times$ National & -.26 & -2.21 & .03 & .02 & .03 \\
\hline \multicolumn{6}{|l|}{ Anxiety Symptoms } \\
\hline Discrimination & .26 & 4.35 & $<.001$ & .07 & $<.001$ \\
\hline Ethnic & -.06 & -0.91 & .37 & & \\
\hline National & -.003 & -0.54 & .96 & & \\
\hline Discrimination $\times$ Ethnic & -.04 & -1.34 & .18 & .01 & .38 \\
\hline Discrimination $\times$ National & .03 & 0.87 & .38 & & \\
\hline Ethnic $\times$ National & .02 & 0.77 & .45 & & \\
\hline Discrimination $\times$ Ethnic $\times$ National & -.26 & -1.87 & .06 & .01 & .06 \\
\hline \multicolumn{6}{|l|}{ Depression Symptoms } \\
\hline Discrimination & .21 & 3.45 & .001 & .07 & $<.001$ \\
\hline Ethnic & -.10 & -1.59 & .11 & & \\
\hline National & -.12 & -1.99 & .05 & & \\
\hline Discrimination $\times$ Ethnic & -.02 & -0.53 & .60 & .002 & .93 \\
\hline Discrimination $\times$ National & -.001 & -0.02 & .98 & & \\
\hline Ethnic $\times$ National & .01 & 0.38 & .70 & & \\
\hline Discrimination $\times$ Ethnic $\times$ National & -.33 & -2.45 & .02 & .02 & .02 \\
\hline \multicolumn{6}{|l|}{ CES-Depression } \\
\hline Discrimination & .33 & 5.50 & $<.001$ & .13 & $<.001$ \\
\hline Ethnic & -.10 & -1.69 & .09 & & \\
\hline National & -.06 & -1.07 & .28 & & \\
\hline Discrimination $\times$ Ethnic & -.04 & -1.55 & .12 & .02 & .16 \\
\hline Discrimination $\times$ National & .03 & 1.32 & .19 & & \\
\hline Ethnic $\times$ National & .03 & 1.09 & .28 & & \\
\hline Discrimination $\times$ Ethnic $\times$ National & -.19 & -1.63 & .11 & .01 & .11 \\
\hline
\end{tabular}

Note . Discrimination = perceived discrimination; Ethnic $=$ ethnic identification, National = national identification. $\beta$ s displayed are from the third step of each regression. 


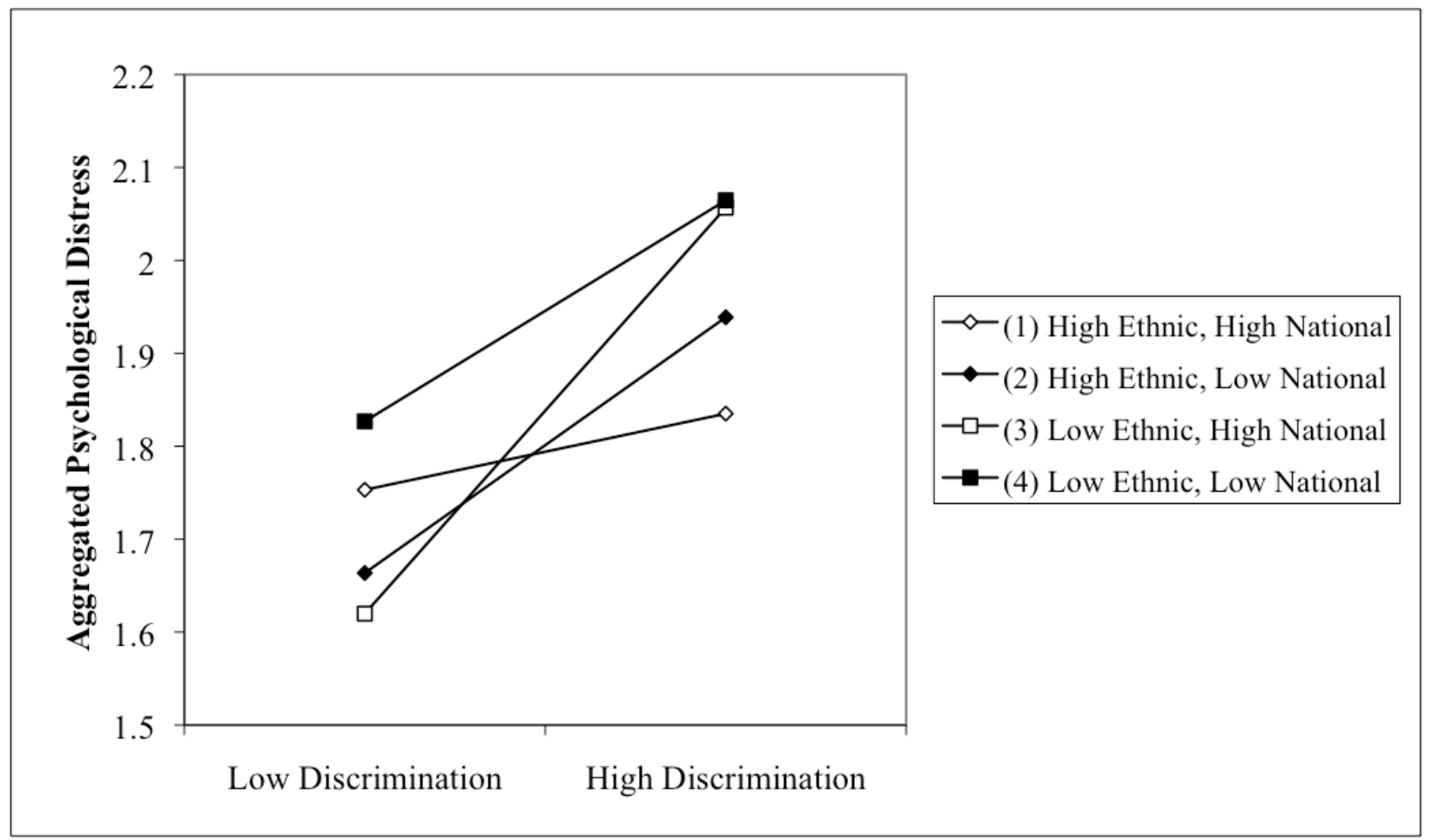

Figure 1. Interaction of perceived discrimination, ethnic identification, and national identification on aggregated psychological distress. Discrimination = perceived discrimination; Ethnic $=$ ethnic identification; National $=$ national identification. 